\title{
Adjunctive corticosteroid therapy for inpatients with Mycoplasma pneumoniae pneumonia
}

\author{
Masato Tashiro ${ }^{1,2^{*}}$ (D) Kiyohide Fushimi ${ }^{3}$, Kei Kawano ${ }^{2}$, Takahiro Takazono ${ }^{1,4}$, Tomomi Saijo ${ }^{4}$, Kazuko Yamamoto ${ }^{4}$, \\ Shintaro Kurihara ${ }^{2}$, Yoshifumi Imamura ${ }^{4}$, Taiga Miyazaki ${ }^{1,4}$, Katsunori Yanagihara ${ }^{5}$, Hiroshi Mukae ${ }^{4}$ \\ and Koichi Izumikawa ${ }^{1,2}$
}

\begin{abstract}
Background: There is conflicting evidence regarding the benefit of adjunctive corticosteroid therapy in patients with Mycoplasma pneumoniae pneumonia. We hypothesised that corticosteroid therapy could reduce mortality and length of stay (LOS) in such patients.

Methods: Adult patients with M. pneumoniae pneumonia from January 2010 to December 2013 were identified from the Japanese Diagnosis Procedure Combination inpatient database. The effects of low-dose and high-dose corticosteroid therapies on mortality, LOS, drug costs and hyperglycaemia requiring insulin treatment were evaluated using propensity score analyses.

Results: Eligible patients ( $n=2228)$ from 630 hospitals were divided into no-corticosteroid $(n=1829)$, low-dose corticosteroid $(n=267)$ and high-dose corticosteroid $(n=132)$ groups. The propensity score-matched pairs were generated from no-corticoid and low-dose corticoid groups (251 pairs), or no-corticoid and high-dose corticosteroid groups (120 pairs). Adjunctive corticosteroid therapy did not decrease 30-day mortality. In addition, both low-dose and high-dose corticosteroid therapies were associated with increases in LOS. Furthermore, hyperglycaemia requiring insulin treatment and drug cost increased with corticosteroid use.
\end{abstract}

Conclusions: Adjunctive treatment with low-dose or high-dose corticosteroids may not be beneficial in $M$. pneumoniae pneumonia.

Keywords: Mycoplasma pneumoniae, Pneumonia, Corticosteroid

\section{Background}

Mycoplasma pneumoniae is the cause of $3-10 \%$ of pneumonia cases [1] and accounts for $10-30 \%$ of all cases of community-acquired pneumonia (CAP) [2, 3]. Most cases of $M$. pneumoniae pneumonia are mild and self-limiting; however, some result in fulminant respiratory failure and may be fatal [4-8]. A previous study reported a mortality rate of $29.4 \%$ among patients with $M$. pneumoniae pneumonia who required intensive care unit (ICU) admission [9]. In addition to antimicrobial agents, corticosteroids

\footnotetext{
* Correspondence: mtashiro@nagasaki-u.ac.jp

'Department of Infectious Diseases, Nagasaki University Graduate School of Biomedical Sciences, 1-7-1 Sakamoto, Nagasaki 852-8501, Japan

${ }^{2}$ Nagasaki University Infection Control and Education Centre, Nagasaki University Hospital, Nagasaki, Japan

Full list of author information is available at the end of the article
}

may be beneficial in the treatment of severe cases of $M$. pneumoniae infections. This is because the pathogenesis of the disease is related to excessive immune responses, including highly activated cell-mediated immune responses and high expressions of cytokines [10-14].

Corticosteroids have been shown to exert a beneficial effect in severe cases of $M$. pneumoniae infection via downregulation of cell-mediated immune responses associated with the pulmonary injury that occurs during the infection [15-18]. However, evidence is limited to case reports and small case series. The results of studies in patients with severe CAP suggest that short-term, late-phase, high-dose corticosteroid treatment is not beneficial [19-22]. Conversely, other studies have reported the efficacy of high-dose methylprednisolone 
therapy in patients with severe M. pneumoniae pneumonia [23-26]. In the present study, we hypothesised that adjunctive corticosteroid therapy may reduce mortality and length of stay (LOS) in patients with severe $M$. pneumoniae pneumonia.

\section{Methods}

\section{Data source}

We used a large nationwide dataset that was obtained from the Japanese Diagnosis Procedure Combination (DPC) system. The database contains claims and abstracted discharge data from $>1000$ participating hospitals, including $92 \%(244 / 266)$ of all tertiary hospitals in Japan [27]. The baseline patient information includes age, sex, primary diagnosis and comorbidities at admission, which are coded according to the International Classification of Diseases, 10th revision (ICD-10) [28]. The database also includes the dosages of all drugs and blood products administered during hospitalisation, as well as the dates of treatment administration. In addition, all interventional procedures are coded with original Japanese codes. Dates of hospital admission and discharge, bedside procedures, drugs administered and discharge status (dead or alive) are recorded using a uniform data submission format. Moreover, diagnostic records are linked to the payment system and attending physicians are required to report objective evidence of each diagnosis made for reimbursement of treatment [27]. The DPC is an administrative database with information inputted at discharge. Thus, for the present study, patient follow-up began on the day of admission and ended on the day of discharge, transfer or death. It was impossible to follow up patients thereafter since no subsequent data were entered.

Data were anonymised on extraction and analysed within the protected environment of the Nagasaki University Hospital (Nagasaki, Japan). The Institutional Review Board of Nagasaki University Hospital waived the requirement of informed consent and approved the study design (Institutional Review Board No. 17012303).

\section{Patient selection}

We identified patients diagnosed with $M$. pneumoniae pneumonia from January 2010 to December 2013. During this period, multiple large epidemics of $M$. pneumoniae infections occurred in Japan [29]. We included patients who were $\geq 18$ years old and had undergone diagnostic tests (paired serologic antibody titres, antigen detection or polymerase chain reaction) confirming $M$. pneumoniae infection. We restricted the analysis to adults because severe $M$. pneumoniae infections occur more frequently in the adult and elderly populations [9]. A single antibody titre and cold agglutinins were not included in the diagnostic tests in this study.
The exclusion criteria were as follows: 1) discharge within 2 days of admission, 2) start intravenous corticosteroid therapy after day 2 of admission and 3) existence of any missing data. Low-dose corticosteroid use was defined as the starting dosages an intravenous infusion of methylprednisolone at $<125 \mathrm{mg}$ (or an equivalent dose of dexamethasone, hydrocortisone, prednisolone or betamethasone) and any higher dose was defined as a high dose [30].

\section{Variables and endpoints}

Comorbidities were evaluated using the Charlson comorbidity index $(\mathrm{CCI})$, which is a method used to predict mortality by classifying or weighting comorbidities [28]. The CCI includes 17 conditions with major impact on survival and is widely used by health researchers to measure case mix and the burden of a disease [31]. For instance, a higher $\mathrm{CCI}$ score reflects a more severe comorbidity. The pneumonia severity was evaluated using the A-DROP system, which is the modified CURB-65 scoring system proposed by The Japanese Respiratory Society [32]. It assesses Age (men $\geq 70$ years, women $\geq 75$ years), Dehydration (existence of a clinical sign of dehydration or blood urea nitrogen level $\geq 210 \mathrm{mg} / \mathrm{L}$ ), Respiratory failure $\left(\mathrm{SpO}_{2} \leq 90 \%\right.$ or $\left.\mathrm{PaO}_{2} \leq 60 \mathrm{mmHg}\right)$, Orientation disturbance (confusion), and a low blood Pressure (systolic blood pressure $\leq 90 \mathrm{mmHg}$ ). The scoring system stratifies patients into four severity classes (mild $=0$; moderate $=1-2$; severe $=3$; and extremely severe $=4-5$ ), and it has an equal ability for predicting the mortality of CAP compared to the CURB-65 scoring system [33]. We assessed medications administered and interventions performed within 2 days of admission except the endpoints.

The endpoints were all-cause 30-day mortality, inhospital hyperglycaemia needing insulin treatment, LOS, duration of antimicrobial treatment and total costs of all the drugs used. We described cost in terms of Japanese Yen (JPY), Euro (EUR) and US Dollar (USD) (1.00 JPY = 0.008587 EUR, 1.00 JPY = 0.009877 USD).

\section{Statistical analysis}

We separately performed one-to-one matching between the no-corticosteroid and the low-dose corticosteroid group, or the no-corticosteroid and the high-dose corticosteroid groups, based on estimated propensity scores for each patient in order to minimise the bias due to confounding variables $[31,34]$. To estimate the propensity score, we fitted a logistic regression model for low-dose or high-dose corticosteroid use as a function of patient and hospital demographics, which included age, sex, CCI score, comorbidities (congestive heart failure, renal disease, liver disease, diabetes with/without chronic complications, chronic obstructive pulmonary disease, bronchial asthma, interstitial lung disease and fibrosis, pleural effusion and 
aspiration or drainage of pleural effusion), parameters of the A-DROP, pneumonia severity, antimicrobial drugs (macrolides, quinolones and tetracyclines), other supportive drugs (catecholamines), interventions (invasive and non-invasive ventilation) and organizational characteristics (ICU admission, academic hospital, and average number of patients in hospital per day) $[6,26,30,35,36]$. The catecholamines included dopamine, dobutamine and noradrenaline (norepinephrine). The c-statistic for evaluating the goodness of fit was calculated and a one-to-one matched analysis using nearest-neighbour matching was performed based on the patients' estimated propensity scores. A match occurred when a patient in the low-dose or high-dose corticosteroid group had an estimated score within 0.2 standard deviations (SDs) of the score of a patient in the no-corticosteroid group [31]. Descriptive statistics have been presented for all patients, including the propensity score-matched patients. Fisher's exact test or Pearson's chi-square test was used to compare discrete variables, whereas the Wilcoxon rank-sum test or Kruskal-Wallis test was used for continuous variables. All the statistical analyses were performed using JMP 12.0 software (SAS Institute, Cary, NC, USA). All the tests were two-tailed and a $p$ value $<0.05$ was considered statistically significant. Data have been expressed as mean \pm SD.

\section{Results}

\section{Patients}

A total of 2718 patients with $M$. pneumoniae pneumonia were admitted to 690 hospitals from January 2010 to December 2013. Among them, 2390 patients were diagnosed by paired antibody titers, 213 by polymerase chain reaction, and 153 by antigen detection (Fig. 1). Overall, 490 patients were excluded based on the various exclusion criteria previously mentioned. As a result, 2228 patients from 630 hospitals were used in the study and were divided into the following groups: no-corticosteroid $(n=1829)$, low-dose corticosteroid $(n=267)$ and high-dose corticosteroid $(n=132)$. From the aforementioned data, the low-dose and high-dose corticosteroid propensity score-matched pairs that were generated were 247 and 122, respectively (Fig. 1). The c-statistic analysis indicated that the goodness of fit values were 0.79 and 0.83 for the low-dose and high-dose groups, respectively, according to the propensity score model.

Table 1 shows the baseline characteristics of the unmatched groups. When the unmatched groups were compared, patients who had more complex comorbidities (i.e., those who were treated with quinolones or were in serious condition and required supportive treatment, mechanical ventilation or care in an ICU) were more likely to receive a corticosteroid treatment. Especially, patients who had bronchial asthma tended to require low-dose corticosteroids $(41.2 \%)$, whereas those who had interstitial lung disease tended to require high-dose corticosteroids (25.8\%). After propensity score-matching, the baseline patient characteristics were similar between the nocorticosteroid $(n=251)$ and low-dose corticosteroid groups $(\mathrm{n}=251)$, as well as between the no-corticosteroid $(n=120)$ and high-dose corticosteroid groups $(n=120)$ (Tables 2 and 3).

The durations of intravenous corticosteroid use were $3.8 \pm 9.7$ days (unmatched group) and 3.4 \pm 9.4 days (matched group) in the low-dose corticosteroid group, and $2.8 \pm 3.6$ days (unmatched group) and $2.9 \pm 3.6$ days (matched group) in the high-dose corticosteroid group. The stated durations included the periods of tapered low-dose corticosteroid use. The starting dosages of methylprednisolone were $56.3 \pm 39.4 \mathrm{mg} /$ day (unmatched group) and $55.7 \pm 39.7 \mathrm{mg} /$ day (matched group) in the low-dose corticosteroid group, and $622 \pm 422 \mathrm{mg} /$ day (unmatched group) and $603 \pm 430 \mathrm{mg} /$ day (matched group) in the high-dose corticosteroid group.

\section{Endpoints}

The outcomes in the unmatched groups showed a higher 30 -day mortality rate $(5.3 \%)$ in the high-dose corticosteroid group than in the no-corticosteroid group $(0.8 \%)$ or low-dose corticosteroid group $(1.9 \%)(p<$ 0.0001) (Table 4). Furthermore, the occurrence of inhospital hyperglycaemia that required insulin treatment, which is an important adverse effect of corticosteroid therapy, was significantly higher at higher corticosteroid dosages (5.7, 11.2 and $23.5 \%$ for the no-corticosteroid, low-dose corticosteroid and high-dose corticosteroid groups, respectively). In addition, LOS significantly increased as corticosteroid dosage was increased (13.1 \pm $12.8, \quad 18.0 \pm 18.8$ and $23.6 \pm 18.5$ days for the nocorticosteroid, low-dose corticosteroid and high-dose corticosteroid groups, respectively). Moreover, the duration of antimicrobial treatment was longer in the low-dose and high-dose corticosteroid groups $(9.3 \pm 7.3$ and $9.5 \pm 6.3$ days, respectively) than in the nocorticosteroid group $(6.8 \pm 4.8$ days $)(p<0.001)$. The total cost of all drugs administered during hospitalisation was higher in the corticosteroid-treated groups than in the no-corticosteroid group $(p<0.0001)$.

In the propensity score-matched groups, low-dose corticosteroid therapy was associated with a long LOS, a long antimicrobial treatment, and a high total cost of drug treatment (Table 5). There were no statistical differences in 30-day mortality and hyperglycaemia requiring insulin treatment in the propensity score analysis between the no-corticosteroid and low-dose corticosteroid groups.

The high-dose corticosteroid group also showed a long LOS, a long antimicrobial treatment and a high total cost of drug treatment (Table 6). There was no statistical 


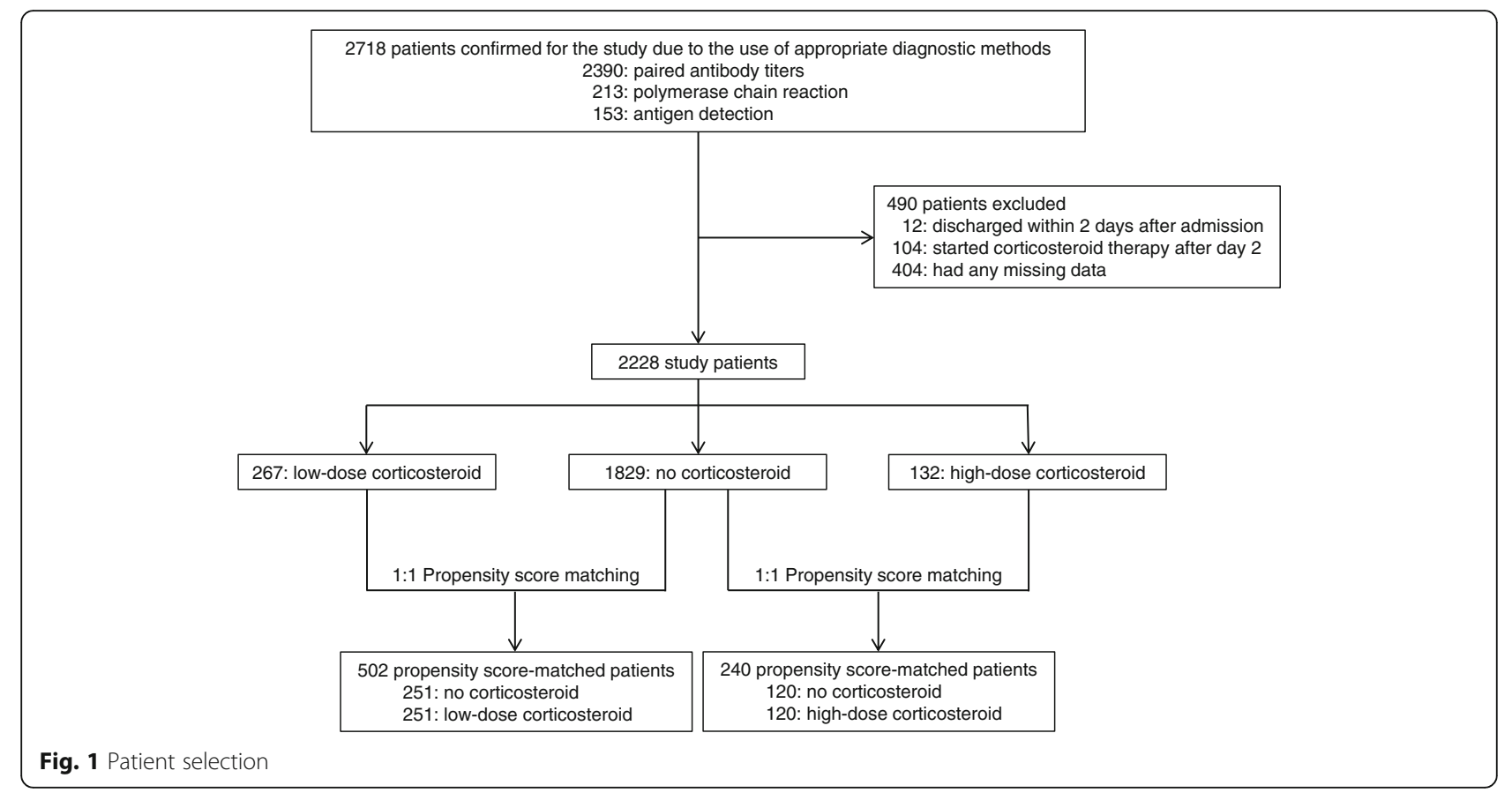

difference in 30-day mortality between the nocorticosteroid and high-dose corticosteroid groups. However, an extremely high prevalence of hyperglycaemia requiring insulin treatment was seen in the highdose corticosteroid group (5.0\% [no-corticosteroid] vs 21.7\% [high-dose corticosteroid], $p=0.0002$ ).

\section{Discussion}

Based on our hypothesis, our aim was to demonstrate the beneficial effects of adjunctive corticosteroid therapy for M. pneumoniae pneumonia. Before conducting this analysis, we had expected that this adjunct therapy could rapidly improve the systemic symptoms of patients and shorten hospitalisation and decrease total treatment costs. However, contrary to our hypothesis, we found that adjunctive treatment with either low-dose or high-dose corticosteroids was associated with a longer LOS and a higher cost of drug treatment during hospitalisation. This means that patients who were administered corticosteroids were not discharged earlier than those who were not administered corticosteroids were. Moreover, a longer LOS is likely to result in the administration of more drugs, which increases the cost of pharmacological treatment. Furthermore, physicians administered corticosteroids as an adjunct therapy in severe cases or to patients who had bronchial asthma or interstitial lung disease. Indeed, from the unmatched group analysis, we found that disease severity was significantly greater in the corticosteroid groups than in the no-corticosteroid group, which clearly influenced mortality, LOS and other outcomes. Hence, we performed a propensity-matched analysis to balance out the outcomes of disease severity. LOS and total drug cost were still higher in the corticosteroid groups than in the no-corticosteroid group. We observed that adjunctive corticosteroid therapy could not reduce LOS or total drug costs although clinicians have observed clinical improvements immediately after administering corticosteroids in some cases [25]. Our results do not necessarily conflict with the outcomes stated in the aforementioned report, which indicated early beneficial effects of adjunctive corticosteroid treatment. This is because later outcomes such as LOS and total drug costs were not stated in the report. In addition, we did not observe a decrease in mortality in the corticosteroid-treated patients, which is a difficult outcome to assess because of the low mortality rate from $M$. pneumoniae infections.

Recent randomised controlled trials (RCTs) and cohort studies that evaluated the use of corticosteroids in adult patients with CAP showed the possibility of obtaining beneficial effects from the treatment, such as decreased treatment failure and shortened time to achieve clinical stability [35, 36]. This call for the use of steroids during the treatment of patients with pneumonia is relevant since $M$. pneumoniae is one of the two most common respiratory pathogens [35]. However, the results from our study do not corroborate those of some previous studies. Torres et al. showed that acute administration of methylprednisolone for patients with severe community-acquired pneumonia and high initial inflammatory response was associated with few treatment failures and low inflammatory responses [35]. Our study included pneumonia patients regardless of the degree of inflammation because we could not use C-reactive 
Table 1 Baseline patient and organization characteristics in the unmatched groups

\begin{tabular}{|c|c|c|c|c|c|c|c|}
\hline \multirow[t]{2}{*}{ Characteristic } & \multirow{2}{*}{\multicolumn{2}{|c|}{ No corticosteroid }} & \multirow{2}{*}{\multicolumn{2}{|c|}{$\begin{array}{l}\text { Low-dose corticosteroids } \\
n=267\end{array}$}} & \multirow{2}{*}{\multicolumn{2}{|c|}{$\begin{array}{l}\text { High-dose corticosteroids } \\
n=132\end{array}$}} & \multirow[b]{2}{*}{$p$ value } \\
\hline & & & & & & & \\
\hline \multicolumn{8}{|l|}{ Patient Characteristics } \\
\hline Age, years & 49.2 & \pm 22.6 & 49.8 & \pm 21.1 & 53.7 & \pm 22.3 & 0.0760 \\
\hline Male & 847 & $(46.3)$ & 106 & $(39.7)$ & 69 & $(52.3)$ & 0.0405 \\
\hline \multicolumn{8}{|l|}{ Preexisting comorbid conditions } \\
\hline Charlson comorbidity index & 0.63 & \pm 1.0 & 1.17 & \pm 1.2 & 0.88 & \pm 0.9 & $<0.0001$ \\
\hline Congestive heart failure & 108 & (5.9) & 35 & $(13.1)$ & 10 & (7.6) & $<0.0001$ \\
\hline Renal disease & 32 & $(1.8)$ & 3 & $(1.1)$ & 2 & $(1.5)$ & 0.7493 \\
\hline Liver disease & 92 & (5.0) & 5 & (1.9) & 6 & $(4.5)$ & 0.0717 \\
\hline Diabetes without chronic complications & 144 & (7.9) & 25 & (9.4) & 17 & $(12.9)$ & 0.1086 \\
\hline Diabetes with chronic complications & 33 & $(1.8)$ & 6 & $(2.2)$ & 1 & $(0.8)$ & 0.5723 \\
\hline Chronic obstructive pulmonary disease & 85 & $(4.6)$ & 22 & $(8.2)$ & 8 & $(6.1)$ & 0.0413 \\
\hline Bronchial asthma & 157 & (8.6) & 110 & $(41.2)$ & 31 & $(23.5)$ & $<0.0001$ \\
\hline Interstitial lung disease and fibrosis & 62 & (3.4) & 19 & (7.1) & 34 & $(25.8)$ & $<0.0001$ \\
\hline Pleural effusion & 117 & (6.4) & 14 & $(5.2)$ & 11 & $(8.3)$ & 0.4910 \\
\hline Aspiration or drainage of pleural effusion & 4 & $(0.2)$ & 3 & $(1.1)$ & 2 & $(1.5)$ & 0.0108 \\
\hline \multicolumn{8}{|l|}{ Pneumonia characteristics } \\
\hline \multicolumn{8}{|l|}{ Parameters of the A-DROP } \\
\hline Age (male $\geq 70$ years, female $\geq 75$ years) & 473 & $(25.9)$ & 58 & $(21.7)$ & 43 & $(32.6)$ & 0.0642 \\
\hline Dehydration & 201 & $(11.0)$ & 39 & (14.6) & 19 & $(14.4)$ & 0.1344 \\
\hline Confusion & 196 & $(10.7)$ & 63 & $(23.6)$ & 56 & $(42.4)$ & $<0.0001$ \\
\hline Respiratory failure & 38 & $(2.1)$ & 12 & $(4.5)$ & 8 & $(6.1)$ & 0.0025 \\
\hline Low blood pressure & 176 & (9.6) & 37 & $(13.9)$ & 17 & $(12.9)$ & 0.0638 \\
\hline \multicolumn{8}{|l|}{ Pneumonia severity } \\
\hline Mild & 1110 & $(60.7)$ & 137 & $(51.3)$ & 48 & $(36.4)$ & $<0.0001$ \\
\hline Moderate & 645 & (35.3) & 111 & $(41.6)$ & 75 & $(56.8)$ & \\
\hline Severe & 58 & (3.2) & 14 & $(5.2)$ & 6 & $(4.5)$ & \\
\hline Extremely severe & 16 & $(0.9)$ & 5 & (1.9) & 3 & $(2.3)$ & \\
\hline \multicolumn{8}{|l|}{ Other treatments } \\
\hline \multicolumn{8}{|l|}{ Anti-mycoplasmal drug use } \\
\hline Macroride & 695 & (38.0) & 104 & (39.0) & 49 & $(37.1)$ & 0.9314 \\
\hline Quinolone & 548 & $(30.0)$ & 116 & $(43.4)$ & 69 & $(52.3)$ & $<0.0001$ \\
\hline Tetracycline & 569 & $(31.1)$ & 78 & $(29.2)$ & 30 & $(22.7)$ & 0.1172 \\
\hline \multicolumn{8}{|l|}{ Other supportive drug use } \\
\hline Catecholamine & 13 & $(0.7)$ & 5 & (1.9) & 8 & (6.1) & $<0.0001$ \\
\hline \multicolumn{8}{|l|}{ Interventions } \\
\hline Invasive ventilation & 10 & $(0.5)$ & 5 & $(1.9)$ & 12 & $(9.1)$ & $<0.0001$ \\
\hline Non-invasive ventilation & 2 & $(0.1)$ & & $(0.0)$ & 2 & $(1.5)$ & 0.0009 \\
\hline \multicolumn{8}{|l|}{ Organization characteristics } \\
\hline Intensive care unit admission & 8 & $(0.4)$ & 5 & $(1.9)$ & 10 & (7.6) & $<0.0001$ \\
\hline Academic hospital & 131 & $(7.2)$ & 16 & $(6.0)$ & 17 & $(12.9)$ & 0.0345 \\
\hline \multicolumn{8}{|c|}{ Average number of patients in hospital per day } \\
\hline$\leq 200$ & 351 & $(19.2)$ & 40 & $(15.0)$ & 26 & $(19.7)$ & 0.2502 \\
\hline $201-600$ & 1194 & (65.3) & 190 & $(71.2)$ & 81 & $(61.4)$ & \\
\hline$\geq 601$ & 284 & (15.5) & 37 & (13.9) & 25 & (18.9) & \\
\hline
\end{tabular}

Data are shown as $\mathrm{n}(\%)$ or mean \pm SD (standard deviation)

protein which is a marker of the inflammation despite we tried to adjust pneumonia severity by using A-DROP system. These differences of results between previous studies and our study indicate that adjunctive steroid therapy could be beneficial in particular cases and that inadequate steroid administration might lead to unfavourable effects. 
Table 2 Baseline patient and organization characteristics in the matched groups of no corticosteroid and low-dose corticosteroid

\begin{tabular}{|c|c|c|c|c|c|}
\hline \multirow[t]{2}{*}{ Characteristic } & \multicolumn{2}{|c|}{ No corticosteroid } & \multicolumn{2}{|c|}{ Low-dose corticosteroids } & \multirow[b]{2}{*}{$p$ value } \\
\hline & $n=25$ & & $n=25$ & & \\
\hline \multicolumn{6}{|l|}{ Patient Characteristics } \\
\hline Age, years & 49.9 & \pm 21.6 & 49.6 & \pm 21.5 & 0.8753 \\
\hline Male & 110 & $(43.8)$ & 101 & $(40.2)$ & 0.4695 \\
\hline \multicolumn{6}{|l|}{ Preexisting comorbid conditions } \\
\hline Charlson comorbidity index & 1.25 & \pm 1.3 & 1.08 & \pm 1.1 & 0.1921 \\
\hline Congestive heart failure & 30 & $(12.0)$ & 30 & $(12.0)$ & 1.0000 \\
\hline Renal disease & 5 & $(2.0)$ & 3 & $(1.2)$ & 0.7244 \\
\hline Liver disease & 6 & $(2.4)$ & 5 & (2.0) & 1.0000 \\
\hline Diabetes without chronic complications & 27 & (10.8) & 25 & $(10.0)$ & 0.8837 \\
\hline Diabetes with chronic complications & 8 & $(3.2)$ & 6 & (2.4) & 0.7875 \\
\hline Chronic obstructive pulmonary disease & 25 & $(10.0)$ & 20 & (8.0) & 0.5324 \\
\hline Bronchial asthma & 103 & $(41.0)$ & 96 & $(38.2)$ & 0.5841 \\
\hline Interstitial lung disease and fibrosis & 12 & $(4.8)$ & 16 & (6.4) & 0.5603 \\
\hline Pleural effusion & 12 & $(4.8)$ & 13 & $(5.2)$ & 1.0000 \\
\hline Aspiration or drainage of pleural effusion & 2 & $(0.8)$ & 2 & $(0.8)$ & 1.0000 \\
\hline \multicolumn{6}{|l|}{ Pneumonia characteristics } \\
\hline \multicolumn{6}{|l|}{ Parameters of the A-DROP } \\
\hline Age (male $\geq 70$ years, female $\geq 75$ years) & 61 & $(24.3)$ & 57 & $(22.7)$ & 0.7523 \\
\hline Dehydration & 40 & $(15.9)$ & 35 & (13.9) & 0.6167 \\
\hline Confusion & 47 & $(18.7)$ & 54 & $(21.5)$ & 0.5043 \\
\hline Respiratory failure & 8 & $(3.2)$ & 9 & (3.6) & 1.0000 \\
\hline Low blood pressure & 29 & $(11.6)$ & 31 & $(12.4)$ & 0.8907 \\
\hline \multicolumn{6}{|l|}{ Pneumonia severity } \\
\hline Mild & 137 & $(54.6)$ & 135 & $(53.8)$ & 0.9527 \\
\hline Moderate & 97 & (38.6) & 100 & (39.8) & \\
\hline Severe & 13 & $(5.2)$ & 11 & $(4.4)$ & \\
\hline Extremely severe & 4 & (1.6) & 5 & (2.0) & \\
\hline \multicolumn{6}{|l|}{ Other treatments } \\
\hline \multicolumn{6}{|l|}{ Anti-mycoplasmal drug use } \\
\hline Macroride & 89 & $(35.5)$ & 94 & $(37.5)$ & 0.7107 \\
\hline Quinolone & 104 & $(41.4)$ & 106 & $(42.2)$ & 0.9279 \\
\hline Tetracycline & 68 & $(27.1)$ & 75 & $(29.9)$ & 0.5531 \\
\hline \multicolumn{6}{|l|}{ Other supportive drug use } \\
\hline Catecholamine & 4 & (1.6) & 4 & (1.6) & 1.0000 \\
\hline \multicolumn{6}{|l|}{ Interventions } \\
\hline Invasive ventilation & 5 & (2.0) & 4 & (1.6) & 1.0000 \\
\hline Non-invasive ventilation & 0 & $(0.0)$ & 0 & $(0.0)$ & \\
\hline \multicolumn{6}{|l|}{ Organization characteristics } \\
\hline Intensive care unit admission & 4 & $(1.6)$ & 5 & (2.0) & 1.0000 \\
\hline Academic hospital & 12 & $(4.8)$ & 15 & $(6.0)$ & 0.6931 \\
\hline \multicolumn{6}{|l|}{ Average number of patients in hospital per day } \\
\hline$\leq 200$ & 44 & $(17.5)$ & 40 & $(15.9)$ & 0.7962 \\
\hline $201-600$ & 169 & $(67.3)$ & 176 & $(70.1)$ & \\
\hline$\geq 601$ & 38 & $(15.1)$ & 35 & $(13.9)$ & \\
\hline
\end{tabular}

Data are shown as $\mathrm{n}(\%)$ or mean \pm SD (standard deviation)

The main strength and the most important characteristic of our study, which makes it unique from previous studies, is that we analysed the effects of corticosteroid therapy in three groups of patients. Recent studies have focused on only low-dose corticosteroid therapy; however, the efficacy of high-dose 
Table 3 Baseline patient and organization characteristics in the matched groups of no corticosteroid and high-dose corticosteroid

\begin{tabular}{|c|c|c|c|c|c|}
\hline \multirow[t]{2}{*}{ Characteristic } & \multicolumn{2}{|c|}{ No corticosteroid } & \multicolumn{2}{|c|}{ High-dose corticosteroids } & \multirow[b]{2}{*}{$p$ value } \\
\hline & $\overline{n=12}$ & & $\overline{n=12}$ & & \\
\hline \multicolumn{6}{|l|}{ Patient Characteristics } \\
\hline Age, years & 55.2 & \pm 22.7 & 52.5 & \pm 22.5 & 0.3607 \\
\hline Male & 65 & $(54.2)$ & 63 & $(52.5)$ & 0.8971 \\
\hline \multicolumn{6}{|l|}{ Preexisting comorbid conditions } \\
\hline Charlson comorbidity index & 1.01 & \pm 1.1 & 0.90 & \pm 0.9 & 0.6511 \\
\hline Congestive heart failure & 11 & $(9.2)$ & 9 & $(7.5)$ & 0.8160 \\
\hline Renal disease & 1 & $(0.8)$ & 2 & $(1.7)$ & 1.0000 \\
\hline Liver disease & 4 & (3.3) & 6 & $(5.0)$ & 0.7486 \\
\hline Diabetes without chronic complications & 15 & $(12.5)$ & 14 & $(11.7)$ & 1.0000 \\
\hline Diabetes with chronic complications & & $(0.0)$ & 1 & $(0.8)$ & 1.0000 \\
\hline Chronic obstructive pulmonary disease & 11 & $(9.2)$ & 8 & $(6.7)$ & 0.6336 \\
\hline Bronchial asthma & 39 & $(32.5)$ & 30 & $(25.0)$ & 0.2538 \\
\hline Interstitial lung disease and fibrosis & 23 & $(19.2)$ & 24 & $(20.0)$ & 1.0000 \\
\hline Pleural effusion & 10 & $(8.3)$ & 10 & $(8.3)$ & 1.0000 \\
\hline Aspiration or drainage of pleural effusion & 1 & $(0.8)$ & 1 & $(0.8)$ & 1.0000 \\
\hline \multicolumn{6}{|l|}{ Pneumonia characteristics } \\
\hline \multicolumn{6}{|l|}{ Parameters of the A-DROP } \\
\hline Age (male $\geq 70$ years, female $\geq 75$ years) & 40 & $(33.3)$ & 36 & $(30.0)$ & 0.6773 \\
\hline Dehydration & 22 & $(18.3)$ & 18 & $(15.0)$ & 0.6037 \\
\hline Confusion & 43 & $(35.8)$ & 45 & $(37.5)$ & 0.8935 \\
\hline Respiratory failure & 6 & $(5.0)$ & 6 & $(5.0)$ & 1.0000 \\
\hline Low blood pressure & 23 & $(19.2)$ & 16 & $(13.3)$ & 0.2937 \\
\hline \multicolumn{6}{|l|}{ Pneumonia severity } \\
\hline Mild & 45 & $(37.5)$ & 48 & $(40.0)$ & 0.7779 \\
\hline Moderate & 64 & $(53.3)$ & 64 & $(53.3)$ & \\
\hline Severe & 5 & $(4.2)$ & 5 & $(4.2)$ & \\
\hline Extremely severe & 6 & (5.0) & 3 & $(2.5)$ & \\
\hline \multicolumn{6}{|l|}{ Other treatments } \\
\hline \multicolumn{6}{|l|}{ Anti-mycoplasmal drug use } \\
\hline Macroride & 44 & $(36.7)$ & 45 & $(37.5)$ & 1.0000 \\
\hline Quinolone & 49 & $(40.8)$ & 59 & $(49.2)$ & 0.2429 \\
\hline Tetracycline & 28 & $(23.3)$ & 28 & $(23.3)$ & 1.0000 \\
\hline \multicolumn{6}{|l|}{ Other supportive drug use } \\
\hline Catecholamine & 8 & $(6.7)$ & 5 & $(4.2)$ & 0.5702 \\
\hline \multicolumn{6}{|l|}{ Interventions } \\
\hline Invasive ventilation & 7 & (5.8) & 7 & $(5.8)$ & 1.0000 \\
\hline Non-invasive ventilation & 1 & $(0.8)$ & 2 & $(1.7)$ & 1.0000 \\
\hline \multicolumn{6}{|l|}{ Organization characteristics } \\
\hline Intensive care unit admission & 5 & $(4.2)$ & 6 & $(5.0)$ & 1.0000 \\
\hline Academic hospital & 11 & $(9.2)$ & 15 & $(12.5)$ & 0.5339 \\
\hline \multicolumn{6}{|l|}{ Average number of patients in hospital per day } \\
\hline$\leq 200$ & 18 & $(15.0)$ & 23 & $(19.2)$ & 0.6922 \\
\hline $201-600$ & 79 & $(65.8)$ & 75 & $(62.5)$ & \\
\hline$\geq 601$ & 23 & $(19.2)$ & 22 & $(18.3)$ & \\
\hline
\end{tabular}

Data are shown as $\mathrm{n}(\%)$ or mean $\pm \mathrm{SD}$ (standard deviation)

methylprednisolone therapy has also been reported for the treatment of severe $M$. pneumoniae pneumonia [23-26]. Therefore, we analysed the efficacy of corticosteroids as an adjunctive therapy at both low and high doses. However, our findings indicate that high-dose corticosteroid therapy might induce several 
Table 4 Comparisons of outcomes between unmatched groups

\begin{tabular}{|c|c|c|c|c|c|c|c|}
\hline \multirow{3}{*}{$\begin{array}{l}\text { Characteristic } \\
\text { 30-day mortality }\end{array}$} & \multirow{2}{*}{\multicolumn{2}{|c|}{$\begin{array}{l}\text { No corticosteroid } \\
n=1829\end{array}$}} & \multirow{2}{*}{\multicolumn{2}{|c|}{$\begin{array}{l}\text { Low-dose corticosteroids } \\
n=267\end{array}$}} & \multirow{2}{*}{\multicolumn{2}{|c|}{$\begin{array}{l}\text { High-dose corticosteroids } \\
n=132\end{array}$}} & \multirow{3}{*}{$\frac{p \text { value }}{<0.0001}$} \\
\hline & & & & & & & \\
\hline & 14 & $(0.8)$ & 5 & (1.9) & 7 & $(5.3)$ & \\
\hline In-hospital hyperglycemia requiring insulin treatment & 104 & $(5.7)$ & 30 & $(11.2)$ & 31 & $(23.5)$ & $<0.0001$ \\
\hline Length of stay, days & 13.1 & \pm 12.8 & 18.0 & \pm 18.8 & 23.6 & \pm 18.5 & $<0.0001$ \\
\hline Length of anitmicrobial treatment, days & 6.8 & \pm 4.8 & 9.3 & \pm 7.3 & 9.5 & \pm 6.3 & $<0.0001$ \\
\hline \multicolumn{8}{|l|}{ Total cost of all drugs in hospitalization } \\
\hline Japanese Yen \pm SD & 49,799 & $\pm 99,142$ & 107,656 & $\pm 243,792$ & 161,980 & $\pm 225,494$ & \multirow[t]{3}{*}{$<0.0001$} \\
\hline Euro $\pm S D$ & 428 & \pm 851 & 924 & \pm 2093 & 1391 & \pm 1936 & \\
\hline US Dollar \pm SD & 492 & \pm 979 & 1063 & \pm 2408 & 1600 & \pm 2227 & \\
\hline
\end{tabular}

Data are shown as $\mathrm{n}(\%)$ or mean $\pm \mathrm{SD}$ (standard deviation)

1.00 Japanese Yen $=0.008587$ Euro

1.00 Japanese Yen $=0.009877$ US Dollar

adverse effects, including hyperglycaemia, which might result in a longer LOS and a higher drug cost due to the need to manage the adverse effects with drugs. These results might apply to the treatment of CAP as well.

This study has some limitations. Firstly, many of the diagnoses of $M$. pneumoniae pneumonia were made based on paired antibody titres. Therefore patients with longer LOS were selected for this analysis, which could be considered as selection bias. Indeed, the mean LOS in this study was longer than 2 weeks. However, the abovementioned limitation affected the no-corticosteroid and corticosteroid-treated groups in similar manners. Secondly, although we used a nationwide database, our study was retrospective, observational and conducted without randomisation. Moreover, bias arising from unmeasured confounders,

Table 5 Comparisons of outcomes between matched groups of no corticosteroid and low-dose corticosteroid

\begin{tabular}{|c|c|c|c|c|c|}
\hline \multirow{3}{*}{$\begin{array}{l}\text { Characteristic } \\
\text { 30-day mortality }\end{array}$} & \multirow{2}{*}{\multicolumn{2}{|c|}{$\begin{array}{l}\text { No corticosteroid } \\
\overline{n=251}\end{array}$}} & \multirow{2}{*}{\multicolumn{2}{|c|}{$\begin{array}{l}\text { Low-dose } \\
\text { corticosteroids } \\
n=251\end{array}$}} & \multirow{3}{*}{$\frac{p \text { value }}{1.0000}$} \\
\hline & & & & & \\
\hline & 5 & $(2.0)$ & 5 & $(2.0)$ & \\
\hline $\begin{array}{l}\text { In-hospital } \\
\text { hyperglycemia } \\
\text { requiring insulin } \\
\text { treatment }\end{array}$ & 20 & $(8.0)$ & 30 & $(12.0)$ & 0.1794 \\
\hline Length of stay, days & 12.8 & \pm 9.1 & 17.6 & \pm 18.0 & 0.0055 \\
\hline $\begin{array}{l}\text { Length of } \\
\text { anitmicrobial } \\
\text { treatment, days }\end{array}$ & 7.1 & \pm 5.1 & 8.9 & \pm 6.7 & 0.0026 \\
\hline \multicolumn{6}{|c|}{ Total cost of all drugs in hospitalization } \\
\hline Japanese Yen \pm SD & 63,265 & $\pm 142,385$ & 103,566 & $\pm 237,757$ & $<0.0001$ \\
\hline Euro $\pm S D$ & 543 & \pm 1223 & 889 & \pm 2042 & \\
\hline US Dollar \pm SD & 625 & \pm 1406 & 1023 & \pm 2348 & \\
\hline
\end{tabular}

Data are shown as $\mathrm{n}(\%)$ or mean \pm SD (standard deviation)

1.00 Japanese Yen $=0.008587$ Euro

1.00 Japanese Yen $=0.009877$ US Dollar such as clinical variables and laboratory values, may have been present although we used propensity score matching to adjust for differences in baseline characteristics and disease severity $[21,35]$. Therefore, large randomised trials are necessary to confirm these results; however, it may not be easy to perform such trials considering that life-threatening $M$. pneumoniae pneumonia is a rare condition. Thus, the present study may provide the best attainable level of evidence on the issue under discussion. Thirdly, there is a possibility that the study population included some patients with bacterial pneumonia caused by other bacteria in addition to M. pneumoniae. However, in routine clinical settings it is difficult to exclude co-infection with other pathologic bacteria in patients diagnosed with severe $M$. pneumoniae pneumonia.

Table 6 Comparisons of outcomes between matched groups of no corticosteroid and high-dose corticosteroid

\begin{tabular}{|c|c|c|c|c|c|}
\hline \multirow{3}{*}{$\begin{array}{l}\text { Characteristic } \\
\text { 30-day mortality }\end{array}$} & \multirow{2}{*}{\multicolumn{2}{|c|}{$\begin{array}{l}\text { No corticosteroid } \\
n=122\end{array}$}} & \multirow{2}{*}{\multicolumn{2}{|c|}{$\begin{array}{l}\text { High-dose } \\
\text { corticosteroids } \\
n=122\end{array}$}} & \multirow{3}{*}{$\frac{p \text { value }}{0.7486}$} \\
\hline & & & & & \\
\hline & 4 & $(3.3)$ & 6 & $(5.0)$ & \\
\hline $\begin{array}{l}\text { In-hospital } \\
\text { hyperglycemia } \\
\text { requiring insulin } \\
\text { treatment }\end{array}$ & 6 & $(5.0)$ & 26 & $(21.7)$ & 0.0002 \\
\hline Length of stay, days & 15.4 & \pm 17.8 & 22.8 & \pm 18.2 & $<0.0001$ \\
\hline $\begin{array}{l}\text { Length of } \\
\text { anitmicrobial } \\
\text { treatment, days }\end{array}$ & 6.9 & \pm 5.2 & 9.4 & \pm 6.4 & 0.0005 \\
\hline \multicolumn{6}{|c|}{ Total cost of all drugs in hospitalization } \\
\hline Japanese Yen \pm SD & 94,905 & $\pm 222,024$ & 145,767 & $\pm 203,214$ & $<0.0001$ \\
\hline Euro $\pm S D$ & 815 & \pm 1907 & 1252 & \pm 1745 & \\
\hline US Dollar \pm SD & 937 & \pm 2193 & 1440 & \pm 2007 & \\
\hline
\end{tabular}

Data are shown as $\mathrm{n}(\%)$ or mean \pm SD (standard deviation)

1.00 Japanese Yen $=0.008587$ Euro

1.00 Japanese Yen $=0.009877$ US Dollar 


\section{Conclusions}

We found that adjunctive treatment with either lowdose or high-dose corticosteroids may not be beneficial in patients with $M$. pneumoniae pneumonia. Based on these findings, clinicians should be more careful if they use corticosteroids to treat adult inpatients with $M$. pneumoniae pneumonia.

\section{Abbreviations}

CCl: Charlson comorbidity index; Cl: Confidence interval; DPC: Japanese Diagnosis Procedure Combination; ICD-10: International Classification of Diseases, tenth revision codes; JCS: Japan Coma Scale; LOS: Length of stay; OR: Odds ratio; SD: Standard deviation

\section{Acknowledgements}

We thank Eishi Ikeda for the advice on the conception of the study.

\section{Funding}

This work was supported by a Grant-in-Aid for Research on Policy Planning and Evaluation from the Ministry of Health, Labour and Welfare (Japan) (H26Seisaku-Shitei-011). The funders had no role in study design, data collection and analysis, decision to publish, or preparation of the manuscript.

\section{Availability of data and materials}

We obtained data from a large, nationwide dataset of the Japanese Diagnosis Procedure Combination system. This dataset was populated from our survey of DPC hospitals; all voluntarily participated (with non-disclosure agreements). Public access to the DPC database is not permitted; the database is for confidential use by our study group. Therefore the raw data in this study cannot be shared.

\section{Authors' contributions}

Study concept, design, data analysis, and manuscript drafting: MT. Data acquisition: KF. Study supervision and critical revision of the manuscript for important intellectual content: KK, TT, TS, K. Yamamoto, SK, YI, TM, K. Yanagihara, HM, and KI. Final approval: MT, KF, KK, TT, TS, K. Yamamoto, SK, $\mathrm{Yl}, \mathrm{TM}, \mathrm{K}$. Yanagihara, HM, and Kl. All authors read and approved the final manuscript.

\section{Ethics approval and consent to participate}

We confirm that any aspect of the work covered in this manuscript that has involved human patients has been conducted with the ethical approval of all relevant bodies and that such approvals are acknowledged within the manuscript. The Institutional Review Board of Nagasaki University Hospital waived the requirement of informed consent and approved the study design (Institutional Review Board No. 17012303).

\section{Consent for publication}

Not applicable

\section{Competing interests}

All authors declare that they have no competing interests.

\section{Publisher's Note}

Springer Nature remains neutral with regard to jurisdictional claims in published maps and institutional affiliations.

\section{Author details}

${ }^{1}$ Department of Infectious Diseases, Nagasaki University Graduate School of Biomedical Sciences, 1-7-1 Sakamoto, Nagasaki 852-8501, Japan. ${ }^{2}$ Nagasaki University Infection Control and Education Centre, Nagasaki University Hospital, Nagasaki, Japan. ${ }^{3}$ Department of Health Policy and Informatics, Graduate School of Medicine, Tokyo Medical and Dental University, Tokyo, Japan. ${ }^{4}$ Second Department of Internal Medicine, Nagasaki University Hospital, Nagasaki, Japan. ${ }^{5}$ Department of Laboratory Medicine, Nagasaki University Hospital, Nagasaki, Japan.
Received: 2 May 2017 Accepted: 21 December 2017

Published online: 29 December 2017

\section{References}

1. Mansel JK, Rosenow EC 3rd, Smith TF, Martin JW Jr. Mycoplasma pneumoniae pneumonia. Chest. 1989:95(3):639-46.

2. Waites KB, Talkington DF. Mycoplasma pneumoniae and its role as a human pathogen. Clin Microbiol Rev. 2004;17(4):697-728.

3. Ishida T, Hashimoto T, Arita M, Tojo Y, Tachibana H, Jinnai M. A 3-year prospective study of a urinary antigen-detection test for Streptococcus pneumoniae in community-acquired pneumonia: utility and clinical impact on the reported etiology. J Infect Chemother. 2004;10(6):359-63.

4. Kannan TR, Hardy RD, Coalson JJ, Cavuoti DC, Siegel JD, Cagle M, Musatovova O, Herrera C, Baseman JB. Fatal outcomes in family transmission of Mycoplasma pneumoniae. Clin Infect Dis. 2012;54(2):225-31.

5. Izumikawa K. Clinical features of severe or fatal Mycoplasma pneumoniae pneumonia. Front Microbiol. 2016;7:800.

6. Miyashita N, Obase Y, Ouchi K, Kawasaki K, Kawai Y, Kobashi Y, Oka M. Clinical features of severe Mycoplasma pneumoniae pneumonia in adults admitted to an intensive care unit. J Med Microbiol. 2007:56(Pt 12):1625-9.

7. Zhang Y, Zhou Y, Li S, Yang D, Wu X, Chen Z. The clinical characteristics and predictors of refractory Mycoplasma pneumoniae pneumonia in children. PLoS One. 2016;11(5):e0156465

8. Wang M, Wang Y, Yan Y, Zhu C, Huang L, Shao X, Xu J, Zhu H, Sun X, Ji W, et al. Clinical and laboratory profiles of refractory Mycoplasma pneumoniae pneumonia in children. Int J Infect Dis. 2014;29:18-23.

9. Khoury T, Sviri S, Rmeileh AA, Nubani A, Abutbul A, Hoss S, van Heerden PV, Bayya $A E$, Hidalgo-Grass $C$, Moses $A E$, et al. Increased rates of intensive care unit admission in patients with Mycoplasma pneumoniae: a retrospective study. Clin Microbiol Infect. 2016;22(8):711-4.

10. Miyashita N, Kawai $Y$, Inamura N, Tanaka T, Akaike H, Teranishi H, Wakabayashi T, Nakano T, Ouchi K, Okimoto N. Setting a standard for the initiation of steroid therapy in refractory or severe Mycoplasma pneumoniae pneumonia in adolescents and adults. J Infect Chemother. 2015;21(3):153-60.

11. Tanaka H, Narita M, Teramoto S, Saikai T, Oashi K, Igarashi T, Abe S. Role of interleukin-18 and T-helper type 1 cytokines in the development of Mycoplasma pneumoniae pneumonia in adults. Chest. 2002;121(5):1493-7.

12. Narita M, Tanaka H, Abe S, Yamada S, Kubota M, Togashi T. Close association between pulmonary disease manifestation in Mycoplasma pneumoniae infection and enhanced local production of interleukin-18 in the lung, independent of gamma interferon. Clin Diagn Lab Immunol. 2000;7(6):909-14.

13. Luo Z, Luo J, Liu E, Xu X, Liu Y, Zeng F, Li S, Fu Z. Effects of prednisolone on refractory Mycoplasma pneumoniae pneumonia in children. Pediatr Pulmonol. 2014;49(4):377-80.

14. Huang L, Gao X, Chen M. Early treatment with corticosteroids in patients with Mycoplasma pneumoniae pneumonia: a randomized clinical trial. J Trop Pediatr. 2014;60(5):338-42.

15. Kawamata R, Yokoyama K, Sato M, Goto M, Nozaki Y, Takagi T, Kumagai H, Yamagata T. Utility of serum ferritin and lactate dehydrogenase as surrogate markers for steroid therapy for Mycoplasma pneumoniae pneumonia. Infect Chemother. 2015;21(11):783-9.

16. Inamura N, Miyashita N, Hasegawa S, Kato A, Fukuda Y, Saitoh A, Kondo E, Teranishi $\mathrm{H}$, Wakabayashi T, Akaike $\mathrm{H}$, et al. Management of refractory Mycoplasma pneumoniae pneumonia: utility of measuring serum lactate dehydrogenase level. J Infect Chemother. 2014;20(4):270-3.

17. Tagliabue C, Salvatore CM, Techasaensiri C, Mejias A, Torres JP, Katz K, Gomez AM, Esposito S, Principi N, Hardy RD. The impact of steroids given with macrolide therapy on experimental Mycoplasma pneumoniae respiratory infection. J Infect Dis. 2008;198(8):1180-8.

18. Remmelts HH, Meijvis SC, Biesma DH, van Velzen-Blad H, Voorn GP, Grutters JC, Bos WJ, Rijkers GT. Dexamethasone downregulates the systemic cytokine response in patients with community-acquired pneumonia. Clin Vaccine Immunol. 2012;19(9):1532-8.

19. Bernard GR, Luce JM, Sprung CL, Rinaldo JE, Tate RM, Sibbald WJ, Kariman K, Higgins S, Bradley R, Metz CA, et al. High-dose corticosteroids in patients with the adult respiratory distress syndrome. N Engl J Med. 1987:317(25):1565-70.

20. Cheng M, Pan ZY, Yang J, Gao YD. Corticosteroid therapy for severe community-acquired pneumonia: a meta-analysis. Respir Care. 2014; 59(4):557-63. 
21. Meijvis SC, Hardeman H, Remmelts HH, Heijligenberg R, Rijkers GT, van Velzen-Blad H, Voorn GP, van de Garde EM, Endeman H, Grutters JC, et al. Dexamethasone and length of hospital stay in patients with communityacquired pneumonia: a randomised, double-blind, placebo-controlled trial. Lancet. 2011;377(9782):2023-30.

22. Nie W, Zhang Y, Cheng J, Xiu Q. Corticosteroids in the treatment of community-acquired pneumonia in adults: a meta-analysis. PLoS One. 2012;7(10):e47926.

23. You SY, Jwa HJ, Yang EA, Kil HR, Lee JH. Effects of Methylprednisolone pulse therapy on refractory Mycoplasma pneumoniae pneumonia in children. Allergy Asthma Immunol Res. 2014;6(1):22-6.

24. Tamura A, Matsubara K, Tanaka T, Nigami H, Yura K, Fukaya T, Methylprednisolone pulse therapy for refractory Mycoplasma pneumoniae pneumonia in children. J Inf Secur. 2008;57(3):223-8.

25. Radisic M, Torn A, Gutierrez P, Defranchi HA, Pardo P. Severe acute lung injury caused by Mycoplasma pneumoniae: potential role for steroid pulses in treatment. Clin Infect Dis. 2000;31(6):1507-11.

26. Izumikawa K, Izumikawa K, Takazono T, Kosai K, Morinaga Y, Nakamura S, Kurihara S, Imamura Y, Miyazaki T, Tsukamoto M, et al. Clinical features, risk factors and treatment of fulminant Mycoplasma pneumoniae pneumonia: a review of the Japanese literature. J Infect Chemother. 2014;20(3):181-5.

27. Tagami T, Matsui $H$, Fushimi $K$, Yasunaga $H$. Intravenous immunoglobulin and mortality in pneumonia patients with septic shock: an observational nationwide study. Clin Infect Dis. 2015:61(3):385-92.

28. Sundararajan V, Quan H, Halfon P, Fushimi K, Luthi JC, Burnand B, Ghali WA. International methodology consortium for coded health I: cross-national comparative performance of three versions of the ICD-10 Charlson index. Med Care. 2007:45(12):1210-5.

29. Yamazaki T, Kenri T. Epidemiology of Mycoplasma pneumoniae infections in Japan and therapeutic strategies for Macrolide-Resistant M. pneumoniae. Front Microbiol. 2016;7:693.

30. Tagami T, Matsui H, Horiguchi H, Fushimi K, Yasunaga H. Low-dose corticosteroid use and mortality in severe community-acquired pneumonia patients. Eur Respir J. 2015;45(2):463-72.

31. Tagami T, Matsui H, Fushimi K, Yasunaga H. Prophylactic antibiotics may improve outcome in patients with severe burns requiring mechanical ventilation: propensity score analysis of a Japanese Nationwide database. Clin Infect Dis. 2016;62(1):60-6.

32. Committee for The Japanese Respiratory Society guidelines for the management of respiratory i. Guidelines for the management of community acquired pneumonia in adults, revised edition. Respirology. 2006;11(Suppl 3):S79-133.

33. Shindo $Y$, Sato $S$, Maruyama E, Ohashi T, Ogawa M, Imaizumi K, Hasegawa Y. Comparison of severity scoring systems A-DROP and CURB-65 for community-acquired pneumonia. Respirology. 2008;13(5):731-5.

34. Stukel TA, Fisher ES, Wennberg DE, Alter DA, Gottlieb DJ, Vermeulen MJ. Analysis of observational studies in the presence of treatment selection bias: effects of invasive cardiac management on AMI survival using propensity score and instrumental variable methods. JAMA. 2007;297(3):278-85.

35. Torres A, Sibila O, Ferrer M, Polverino E, Menendez R, Mensa J, Gabarrus A, Sellares J, Restrepo Ml, Anzueto A, et al. Effect of corticosteroids on treatment failure among hospitalized patients with severe community acquired pneumonia and high inflammatory response: a randomized clinical trial. JAMA. 2015;313(7):677-86.

36. Blum CA, Nigro N, Briel M, Schuetz P, Ullmer E, Suter-Widmer I, Winzeler B, Bingisser R, Elsaesser H, Drozdov D, et al. Adjunct prednisone therapy for patients with community-acquired pneumonia: a multicentre, double-blind, randomised, placebo-controlled trial. Lancet. 2015;385(9977):1511-8.

\section{Submit your next manuscript to BioMed Central and we will help you at every step:}

- We accept pre-submission inquiries

- Our selector tool helps you to find the most relevant journal

- We provide round the clock customer support

- Convenient online submission

- Thorough peer review

- Inclusion in PubMed and all major indexing services

- Maximum visibility for your research

Submit your manuscript at www.biomedcentral.com/submit

) Biomed Central 